\title{
Dysfunctional Light-Evoked Regulation of cAMP in Photoreceptors and Abnormal Retinal Adaptation in Mice Lacking Dopamine D4 Receptors
}

\author{
Izhak Nir, ${ }^{1}$ Joseph M. Harrison, ${ }^{2}$ Rashidul Haque, ${ }^{3}$ Malcolm J. Low, ${ }^{4}$ David K. Grandy, ${ }^{5}$ Marcelo Rubinstein, ${ }^{6}$ \\ and P. Michael luvone ${ }^{3}$ \\ Departments of ${ }^{1}$ Pharmacology and ${ }^{2}$ Ophthalmology, The University of Texas Health Science Center at San Antonio, \\ Texas 78229, ${ }^{3}$ Department of Pharmacology, Emory University School of Medicine, Atlanta, Georgia 30322, ${ }^{4}$ Vollum \\ Institute and ${ }^{5}$ Department of Physiology and Pharmacology, Oregon Health and Science University, Portland, Oregon \\ 97201, 6/nstituto de Investigaciones en Ingeniería Genética y Biología Molecular, Consejo Nacional de Investigaciones \\ Científicas y Técnicas de Argentina, and Department of Biological Science, University de Buenos Aires, 1428 Argentina
}

Dopamine is a retinal neuromodulator that has been implicated in many aspects of retinal physiology. Photoreceptor cells express dopamine D4 receptors that regulate cAMP metabolism. To assess the effects of dopamine on photoreceptor physiology, we examined the morphology, electrophysiology, and regulation of cAMP metabolism in mice with targeted disruption of the dopamine D4 receptor gene. Photoreceptor morphology and outer segment disc shedding after light onset were normal in D4 knock-out (D4KO) mice. Quinpirole, a dopamine D2/ D3/D4 receptor agonist, decreased cAMP synthesis in retinas of wild-type (WT) mice but not in retinas of D4KO mice. In WT retinas, the photoreceptors of which were functionally isolated by incubation in the presence of exogenous glutamate, light also suppressed cAMP synthesis. Despite the similar inhibition of cAMP synthesis, the effect of light is directly on the photoreceptors and independent of dopamine modulation, because it was unaffected by application of the D4 receptor antagonist L-745,870. Nevertheless, compared with WT retinas, basal

In the mammalian retina, dopamine (DA) is synthesized and released by a subset of dopaminergic amacrine and interplexiform cells (Nguyen-Legros et al., 1981; Vesaux-Botteri et al., 1986). Released DA acts on two families of G-protein-coupled receptors: the D1 family, which includes the D1 and D5 subtypes, and the D2 family, consisting of the D2, D3, and D4 subtypes (Civelli et al., 1993; Gingrich and Caron, 1993; Nguyen-Legros at al., 1999). Activation of DA D2/D4 receptors on retinal photoreceptors affects a variety of photoreceptor functions, including: disc shedding (Besharse et al., 1988), cone contraction (Pierce and Besharse, 1985; Dearry and Burnside, 1986; Hillman et al., 1995), melatonin synthesis (Iuvone, 1986; Iuvone and Besharse, 1986; Cahill and Besharse, 1991; Zawilska et al., 1995), $\mathrm{Na}^{+}, \mathrm{K}+-$

Received Aug. 28, 2001; revised Dec. 20, 2001; accepted Dec. 28, 2001.

This work was supported by National Institutes of Health Grants RO1-EY10286 (I.N.), RO1-EY04864 (P.M.I.), and RO1-DA12062 (DKG), Research to Prevent Blindness, Inc. (New York, NY), and the San Antonio Area Foundation (J.M.H), the Universidad de Buenos Aires and International Research Scholar grant from Howard Hughes Medical Institute (M.R.). We thank Sylvia Gill and Katherine Suchland for expert technical assistance.

Correspondence should be addressed to P. Michael Iuvone, Department of Pharmacology, Emory University School of Medicine, 1510 Clifton Road, Atlanta, GA 30322. E-mail: mivuone@pharm.emory.edu.

Copyright (C) 2002 Society for Neuroscience $0270-6474 / 02 / 222063-11 \$ 15.00 / 0$
CAMP formation was reduced in the photoreceptors of D4KO retinas, and light had no additional inhibitory effect. The results suggest that dopamine, via D4 receptors, normally modulates the cascade that couples light responses to adenylyl cyclase activity in photoreceptor cells, and the absence of this modulation results in dysfunction of the cascade. Dark-adapted electroretinogram (ERG) responses were normal in D4KO mice. However, ERG b-wave responses were greatly suppressed during both light adaptation and early stages of dark adaptation. Thus, the absence of D4 receptors affects adaptation, altering transmission of light responses from photoreceptors to inner retinal neurons. These findings indicate that dopamine D4 receptors normally play a major role in regulating photoreceptor cAMP metabolism and adaptive retinal responses to changing environmental illumination.

Key words: dopamine; dopamine D4 receptors; photoreceptor; adaptation; cAMP; retina; light adaptation; electroretinogram

ATPase activity (Shulman and Fox, 1996), balance of rod-cone inputs to horizontal cells (Witkovsky et al., 1989), gap junction connectivity between rods and cones (Krizaj et al., 1998), and modulation of photoreceptor calcium currents (Stella and Thoreson, 2000).

In situ hybridization analysis of the mouse retina revealed that D4 receptors are localized to the photoreceptor layer of the mouse retina (Cohen et al., 1992). The D4 receptors on the photoreceptor cells are apparently activated by DA that reaches the photoreceptors cells by diffusion (Nguyen-Legros et al., 1990; Besharse and Iuvone, 1992; Witkovsky et al., 1993). Stimulation of D4 receptors decreases cAMP formation, caused by coupling of the receptors to a GTP-binding protein, which inhibits the activity of adenylyl cyclase (Kebabian and Calne, 1979; Schorderet and Nowak, 1990; Schwartz et al., 1992). In a study of the mouse retina, it was shown that activation of the D4 receptors on the photoreceptor cells modulates a light-sensitive pool of cAMP (Cohen and Blazynski, 1990; Cohen et al., 1992). Although D4 receptor mRNA is also expressed to a limited extent in the inner nuclear and ganglion cell layers (Cohen et al., 1992), the receptors, if functionally expressed, do not appear to contribute significantly to the regulation of retinal cAMP; D4 receptor agonists have no effect on cAMP levels of $r d / r d$ retinas, which lack pho- 
toreceptor cells (Cohen and Blazynski, 1990). In view of the proposed role of cAMP in mediating various light-evoked photoreceptor functions, the findings that D4 receptors regulate cAMP levels in photoreceptors is of importance for understanding the role of DA in photoreceptor biology. In the present study we evaluated the role of D4 receptors in regulation of photoreceptor cAMP levels and photoreceptor functions by analysis of mice lacking dopamine D4 receptors (Rubinstein et al., 1997).

A preliminary report of some of these results was presented (Harrison et al., 2000).

\section{MATERIALS AND METHODS}

Animals. Handling of animals conformed to the principles regarding the care and use of animals adopted by the American Physiological Society and Society for Neuroscience. D4R-/- mice, lacking dopamine D4 receptors [D4 knock-out (KO)], and normal D4R+/+ control [wild-type (WT)] mice on a C57BL/6J background were studied (Rubinstein et al., 1997). D4R +/- mice were repeatedly backcrossed to WT C57BL/6J, and N-6 to N-11 generations were analyzed. Mice were genotyped by Southern analysis (Rubinstein et al., 1997). The mice were housed in lightproof rooms and kept on a $12 \mathrm{hr}$ light/dark cycle, with lights on at 8:00 A.M. Fluorescent tubes provided illumination of 3-5 footcandles (fc) at cage level. Mice were killed by cervical dislocation.

Analysis of cAMP in vitro. Analysis was performed as described by Cohen et al. (1992). Retinas were isolated from dark-adapted mice and placed in ice cold Earle's saline containing (in mM): $115 \mathrm{NaCl}, 3 \mathrm{KCl}, 1.8$ $\mathrm{CaCl}_{2}, 0.8 \mathrm{MgSO}_{4}, 26 \mathrm{NaHCO}_{3}, 0.9 \mathrm{NaH}_{2} \mathrm{PO}_{4}$, and 5.5 dextrose, $\mathrm{pH}$ 7.4, in an atmosphere of $5 \% \mathrm{CO}_{2}$ and $95 \% \mathrm{O}_{2}$. Isolation was performed under dim red light (safety light filter, model 1; Eastman Kodak, Rochester, NY). Isolated retinas were placed individually in a multiwell plate in $0.7 \mathrm{ml}$ incubation medium containing Earle's salt solution plus $1 \mathrm{~mm}$ 3-isobutyl-1-methylxanthine (IBMX). In some experiments, $10 \mathrm{~mm}$ glutamate was added. Exogenous glutamate blocks synaptic transmission from photoreceptor cells to second order neurons, suppressing the light response of the inner retina without affecting that of the photoreceptor (Sillman et al., 1969; Dowling and Ripps, 1972). This functionally isolates the photoreceptor response to light. Incubation was performed at $37^{\circ} \mathrm{C}$ in an atmosphere of $5 \% \mathrm{CO}_{2}$ and $95 \% \mathrm{O}_{2}$. Retinas analyzed under dark conditions were incubated for $9 \mathrm{~min}$ in the dark. Retinas analyzed under light conditions were incubated for $2 \mathrm{~min}$ in the dark then illuminated for $7 \mathrm{~min}$ with fluorescent light (GE Cool White Light) with an illumination of $100 \mathrm{fc}$ at well level. Immediately after incubation the retinas were frozen in liquid $\mathrm{N}_{2}$.

For activation of DA D4 receptors, $1 \mu \mathrm{M}$ quinpirole, a D2/D4 receptor agonist, was added to the incubation medium (Research Biochemicals, Natick, MA) for the 9 min incubation in the dark. For blocking D4 receptors, $10-50 \mu \mathrm{M} \mathrm{L}-745,870$, a selective D4 receptor antagonist, was used (Tocris Cookson, Ballwin, MO). For blocking D1 receptors, $10 \mu \mathrm{M}$ $\mathrm{SCH} 23390$, a selective D1 antagonist, was added to the incubation medium (Research Biochemicals).

Cyclic nucleotide assays. Frozen retinas were homogenized with $6 \%$ trichloroacetic acid. The homogenate was centrifuged, and the supernatant fraction washed repeatedly with ethyl ether, dried, and then reconstituted in cAMP assay buffer (sodium acetate buffer, $\mathrm{pH}$ 6.2). To determine the recovery of cAMP during extraction, $\sim 4000 \mathrm{cpm}$ of $\left[{ }^{3} \mathrm{H}\right] \mathrm{cAMP}$ tracer was added to each sample extract. The cAMP was acetylated and measured with a commercial radioimmunoassay kit (DuPont NEN, Boston, MA). Protein content was determined by the method of Lowry et al. (1951).

$D A$ turnover. Synthesis of dopamine from L-tyrosine is a two step process: (1) hydroxylation by tyrosine hydroxylase $(\mathrm{TH})$ to produce L-3,4-dihydroxyphenylalanine (L-DOPA); and (2) decarboxylation of DOPA by aromatic L-amino acid (DOPA) decarboxylase to produce dopamine. DA synthesis and utilization were analyzed after inhibition of DOPA decarboxylase with $m$-hydroxybenzylhydrazine (NSD-1015; Sigma, St. Louis, MO). Inhibition of DOPA decarboxylase results in accumulation of DOPA, which is used as an estimation of in situ TH activity and DA synthesis. Utilization of DA is reflected by the decline in DA levels after decarboxylase inhibition. Isolated retinas were incubated in the presence of $100 \mu \mathrm{M}$ NSD-1015 for $20 \mathrm{~min}$ in light or darkness. DA and DOPA levels were analyzed by HPLC with electrochemical (EC) detection, as described previously (Nir and Iuvone, 1994).
Morphology. Eyes were placed in $4 \%$ formaldehyde and $2 \%$ glutaraldehyde in $0.1 \mathrm{M}$ phosphate buffer, $\mathrm{pH} 7.0$, for fixation. After $30 \mathrm{~min}$, the eyes were bisected along the vertical meridian, and the two hemispheres were fixed for an additional $3 \mathrm{hr}$. The tissue was then treated in $1 \%$ OsO4, dehydrated, and embedded in an epoxy resin. Thick $(1 \mu \mathrm{m})$ and thin $(80-100 \mathrm{~nm})$ sections were cut at different sites along the centralperipheral axis of the retina and stained with uranyl and lead salts. Photoreceptor cell morphology and phagosomes in the retinal pigment epithelium (RPE) were viewed by light and electron microscopy (Philips 301 transmission electron microscope).

For quantification of number of phagosomes, $1 \mu \mathrm{m}$ sections were stained with methylene blue or with a 1:1 mixture of azure II and methylene blue (Grace et al., 1999). All densely stained inclusion bodies in the pigment epithelial cell somas and apical processes, with diameter of $1 \mu \mathrm{m}$ and larger were counted as a measure of disk shedding (LaVail, 1976). In each retina both hemispheres were analyzed. In each hemisphere, 10 consecutive fields $(100-\mu \mathrm{m}$-long), extending from the optic nerve head toward the equator, were analyzed. The data are presented as number of phagosomes per $100 \mu \mathrm{m}$ length of pigment epithelium. Measurements of the length of outer segment and width of the outer nuclear layer were carried at four to six sites in the posterior retina, 50-100 $\mu \mathrm{m}$ apart.

Electroretinogram. The mice were tested after $12 \mathrm{hr}$ of dark adaptation. They were brought to the laboratory in opaque cages and were prepared for recording under dim red (Kodak safety light filter 1) light. They were anesthetized with intraperitoneal ketamine and xylazine (75 and 10 $\mathrm{mg} / \mathrm{kg}$, respectively). Their pupils were dilated with $1 \%$ tropicamide and phenylephrine, and their corneas were anesthetized with procaine and protected by $2.5 \%$ hydroxypropyl methylcellulose. A carbon fiber active electrode was placed on the corneal apex and referenced to a gold ring electrode on the tongue. The ground was a subdermal platinum needle electrode near the tail. Adjustments were made, if necessary, to achieve an active to reference impedance $<30,000 \Omega$ (model EZM5; Grass Instruments, Quincy, MA) and a ground to reference impedance $<10,000 \Omega$. The mice were placed prone on a catalytic heating pad (Deltaphase Isothermal Pad; Braintree Scientific, Inc., Braintree, MA). The eye was centered in the aperture of the ganzfeld (LKC Technologies 2503-0.4 m diameter partial sphere). Bioelectric signals were amplified with a gain of 10,000 and filtered from $1-1000 \mathrm{~Hz}$ (model P5 amplifier; Grass Instruments). The amplified signals were digitized and stored by a digital oscilloscope (model 4094 B; Nicolet Instrument Technologies, Inc., Madison, WI). The signals were digitized at 10,000 samples per second with 12 bit analog-to-digital resolution in a trace of $0.396 \mathrm{sec}$ duration. The mice were allowed to dark adapt for another $10 \mathrm{~min}$ after the preparation was complete.

Electroretinograms (ERGs) were produced by 10 ganzfeld flash intensities ( 9 scotopic $\mathrm{cd} \cdot \mathrm{sec}^{-1} \cdot \mathrm{m}^{-1}$ (standard stimulus) to $2 \times 10^{-3}$ scotopic $\mathrm{cd} \cdot \mathrm{sec}^{-1} \cdot \mathrm{m}^{-1}$ ). The flash stimulus source (model PS22; Grass Instruments) illuminated the eye by diffuse reflection off the interior surface of the ganzfeld. Maximum flash luminance was 9 scotopic $\mathrm{cd} \cdot \mathrm{sec}^{-1} \cdot \mathrm{m}^{-1}$ and was measured with a light meter (IL 1700; International Light, Inc.; Newburyport, MA) and detector (models SED033, 3770 with diffuser, L30 71 and scotopic filter, ZCIE 19984) whose calibration is traceable to the National Institute of Standards and Technology. After the intensity series, an incandescent background light (58 $\mathrm{cd} / \mathrm{m} ; 1^{\circ}$ spotmeter; Minolta USA, Ramsey, NJ) sufficient to desensitize the rod system was turned on, and ERGs produced by the standard stimulus were recorded every $2 \mathrm{~min}$ for $20 \mathrm{~min}$. The background was then turned off, and ERGs were produced by the standard stimulus every 2 min for the first 12 min of dark adaptation. The a- and b-wave amplitudes and b-wave implicit times were measured offline. Oscillatory potentials were extracted offline by a digital bandpass filter set at $40-300 \mathrm{~Hz}$ (Vu-PointII; Maxwell Laboratories, Inc., La Jolla, CA). Time-to-peak and peak-to-peak amplitude of the oscillatory potentials were measured.

\section{RESULTS \\ Photoreceptor morphology and outer segment disc shedding}

The lack of D4 receptors did not adversely affect photoreceptor viability. Measurement of the photoreceptor nuclear layer thickness did not reveal differences between D4KO and WT retinas, indicating comparable survival of photoreceptors (Table 1). Morphologically, the photoreceptors in the D4KO retinas demon- 


\begin{tabular}{|c|c|c|c|c|}
\hline Genotype & $N$ & $\begin{array}{l}\text { Phagocytosis of shed OS } \\
\text { (phagosomes } / 100 \mu \mathrm{m} \text { ) }\end{array}$ & $\begin{array}{l}\text { OS length } \\
(\mu \mathrm{m})\end{array}$ & $\begin{array}{l}\text { ONL thickness } \\
(\mu \mathrm{m})\end{array}$ \\
\hline WT & 5 & $8.50 \pm 0.33$ & $24.9 \pm 1.0$ & $45.1 \pm 1.0$ \\
\hline $\mathrm{D} 4 \mathrm{KO}$ & 5 & $8.33 \pm 0.41$ & $23.6 \pm 0.9$ & $44.7 \pm 1.0$ \\
\hline
\end{tabular}

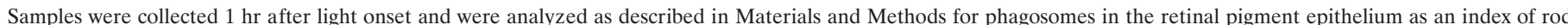

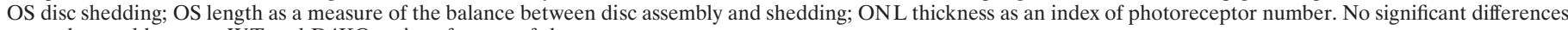
were observed between WT and D4KO retinas for any of these parameters.

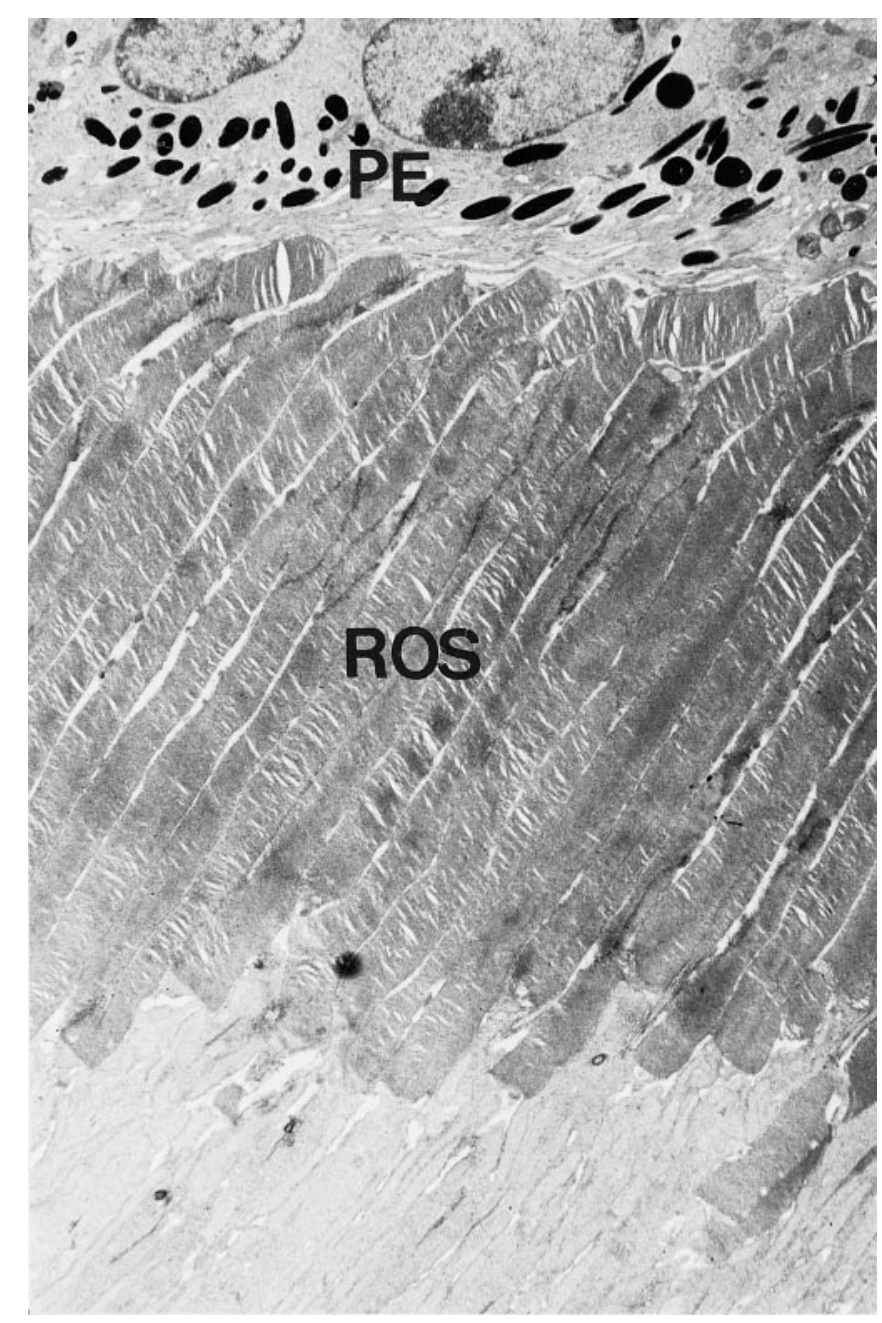

Figure 1. Ultrastructure of photoreceptors in D4KO mice. Rod photoreceptors with normal morphology of outer segments $(R O S)$ are seen. The distal ends of the photoreceptor outer segments are in close proximity to the RPE cells $(P E)$. Magnification, 3610×.

strated normal ultrastructure of intact outer segments in close association with the RPE (Fig. 1). Outer segment length of D4KO retinas was not different from that in WT (Table 1 ). In view of the possible role of $\mathrm{D} 2 / \mathrm{D} 4$ receptors in regulation of disc shedding (Besharse et al., 1988), the presence of shed rod outer disc membranes in the RPE of D4KO at the beginning of the day period was investigated under light and electron microscopy. At 60-90 min into the day period, when the daily peak of rod disc shedding and phagocytosis occurs, numerous shed rod outer segments discs were observed in the RPE of D4KO retinas, similar to that seen in the WT retina. Figure 2 shows the engulfment of a packet of shed outer segment disc membranes by RPE

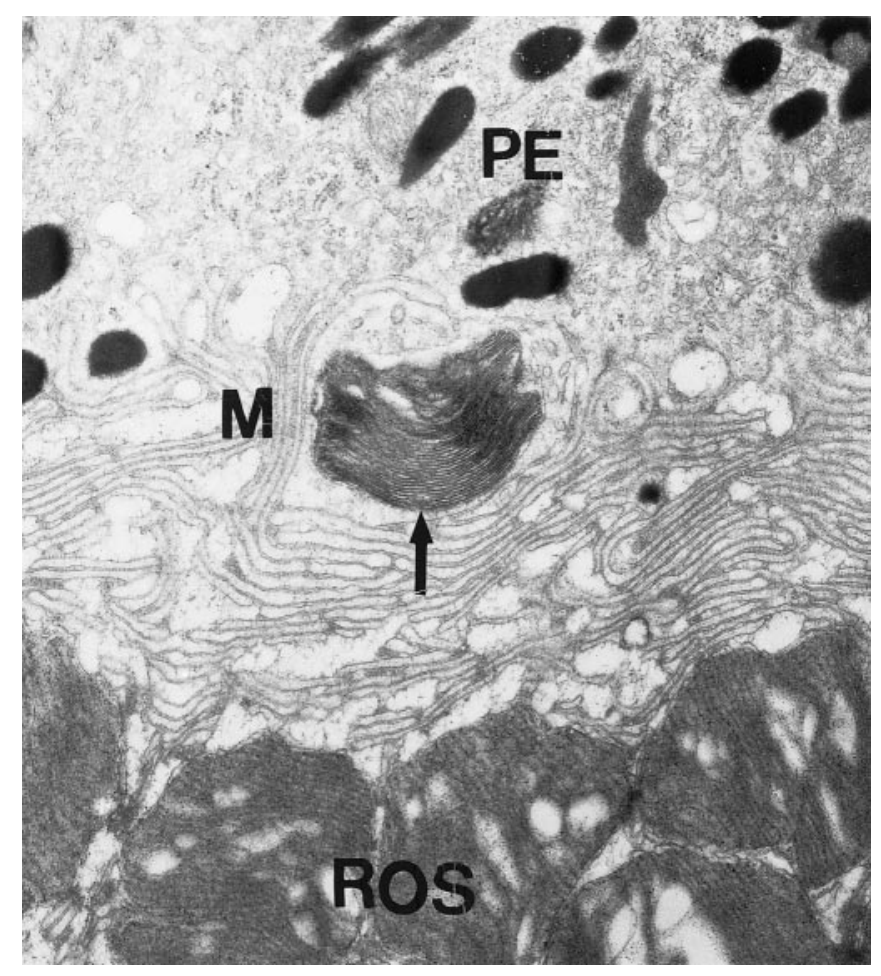

Figure 2. Disc shedding and phagocytosis in D4KO mice. Shedding of outer segment discs and phagocytosis by the RPE are evident by the presence of shed rod outer segment disk packet (arrow) engulfed by RPE microvilli $(M)$. Magnification, 17,290×.

microvilli in the D4KO retina. The number of phagosomes 60-90 min after light onset was similar in RPE of D4KO and WT mice (Table 1). Thus, it appears that disc shedding and phagocytosis are not severely affected in the D4KO retinas.

\section{Regulation of cAMP levels in WT and D4KO photoreceptors}

Light-mediated regulation of $c A M P$ levels in retina in vitro

To assess the effect of light on retinal cAMP levels, isolated retinas were incubated for $9 \mathrm{~min}$ in darkness or for $2 \mathrm{~min}$ in darkness followed by $7 \mathrm{~min}$ in light. cAMP levels in illuminated WT retinas were reduced by $28 \%$ from levels measured in darkness (Table 2). In striking contrast, illumination of the D4KO retinas resulted in a $56 \%$ increase of cAMP levels from those measured in the dark.

Light stimulates dopamine synthesis and release in mammalian retina (Kramer, 1971; Iuvone et al., 1978; Nir et al., 2000). The increase of cAMP levels in the $\mathrm{D} 4 \mathrm{KO}$ retinas in light can be explained by the dopamine D1 receptor-mediated increase of cAMP formation in inner retinal neurons in the absence of downregulation of cAMP in the D4 deficient photoreceptors. 
Table 2. Regulation of cAMP in vitro in a medium without glutamate: levels of cAMP in WT and D4KO retinas in dark and light

\begin{tabular}{llc} 
Mice & Conditions & cAMP \\
\hline WT & Dark & $144.3 \pm 9.7(n=7)$ \\
WT & Light & $103.9 \pm 10.8(n=6)^{a}$ \\
D4KO & Dark & $84.9 \pm 5.3(n=6)$ \\
D4KO & Light & $132.0 \pm 12(n=5)^{b}$
\end{tabular}

Two-factor ANOVA: genotype $\times$ treatment, $F=24.205 ; p<0.001$.

${ }^{a} p<0.003$ versus WT dark.

${ }^{b} p=0.002$ versus D4KO dark.

Table 3. Regulation of cAMP in vitro in a medium without glutamate: levels of cAMP in D4KO retinas in light in the presence of D1 receptor antagonist SCH 23390

\begin{tabular}{llr} 
Mice & Conditions & cAMP \\
\hline D4KO & Dark (control) & $82.4 \pm 8.5(n=4)$ \\
D4KO & Light (control) & $109.4 \pm 8.9(n=7)^{a}$ \\
D4KO & Light + SCH 23390 & $74.2 \pm 5.5(n=7)^{b}$
\end{tabular}

$a_{p}<0.05$ versus D4KO dark.

${ }^{b} p=0.01$ versus D4KO light; $p=0.504$ versus D4KO dark.

This was shown by incubating D4KO retinas in the presence of the D1 receptor antagonist SCH23390, which completely blocked the light-evoked increase of cAMP levels in D4KO retinas (Table 3 ). Hence, the increase of cAMP levels in illuminated D4KO retinas is attributable to light-evoked DA release and activation of D1 receptors localized on inner retinal neurons.

\section{Regulation of cAMP levels in functionally isolated} photoreceptor cells of WT mice

Exogenous glutamate blocks synaptic transmission from photoreceptor cells to second order neurons, suppressing the light response of the inner retina without affecting that of the photoreceptor (Sillman et al., 1969; Dowling and Ripps, 1972). This functionally isolates the photoreceptor response to light. In the presence of exogenous glutamate, illumination of WT retinas reduced cAMP levels by $\sim 60 \%$ from levels measured in dark (Fig. 3). This reduction is larger than that observed in the absence of glutamate, presumably because glutamate blocks the transsynaptic light-evoked release of dopamine and activation of inner retinal dopamine D1 receptors. Pharmacological activation of dopamine receptors with quinpirole, a D2/D3/D4-receptor agonist, mimics the effect of light on cAMP levels (Fig. 3) by stimulating dopamine D4 receptors on photoreceptor cells (Cohen and Blazynski, 1990; Cohen et al., 1992). The inhibition of cAMP formation by quinpirole in dark-adapted, glutamate-treated retinas was significantly antagonized by $10 \mu \mathrm{M}$ L-745,870, a specific dopamine D4 receptor antagonist (Fig. 3). In contrast, neither 10 nor $50 \mu \mathrm{M} \mathrm{L}-745,870$ significantly affected the light-evoked inhibition of cAMP formation. Hence, the light-evoked inhibition of cAMP formation in the presence of exogenous glutamate occurs by a dopamine-independent mechanism and presumably reflects a direct effect of light on the photoreceptor cells.

In the intact mouse retina, light exposure activates dopamine amacrine cells, resulting in accelerated dopamine turnover (Nir et al., 2000). If exogenous glutamate eliminates the inner retinal response to light exposure by blocking synaptic transmission from photoreceptors to second order neurons (Sillman et al., 1969; Dowling and Ripps, 1972), incubation of retinas in the presence

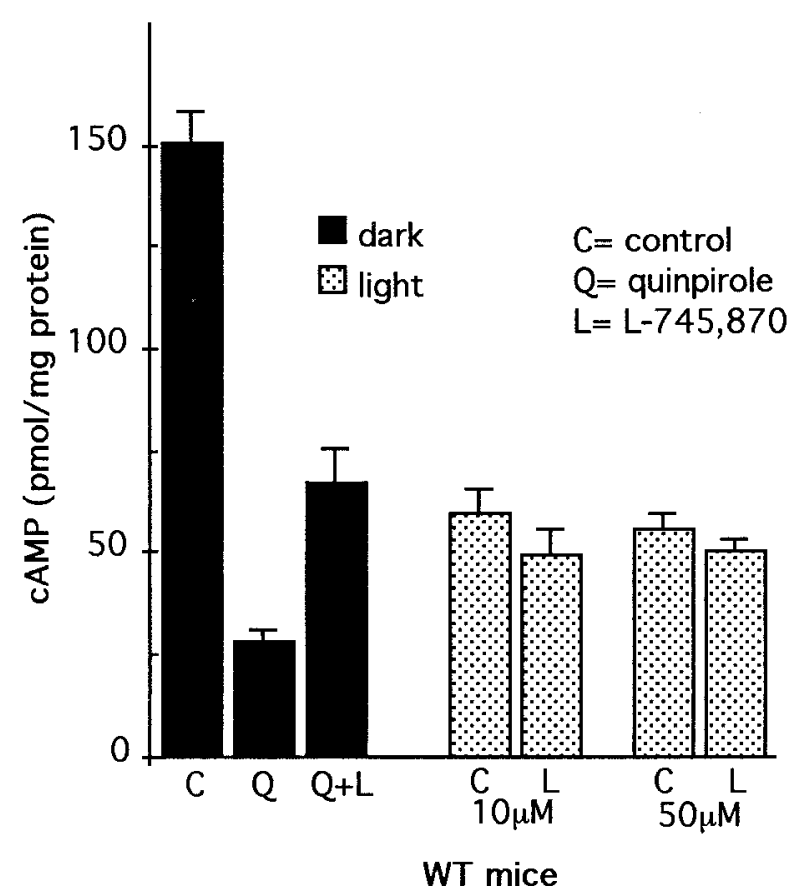

Figure 3. Regulation of cAMP levels in WT retina in a medium containing exogenous glutamate. Isolated retinas were incubated in the presence of $10 \mathrm{~mm}$ glutamate, as described in Materials and Methods, to functionally isolate the photoreceptor response to light. Retinas were incubated in the dark, in the presence of quinpirole alone $(Q ; 1 \mu \mathrm{M})$, or with quinpirole and the specific D4 receptor antagonist L-745,870 $(Q+L$; $10 \mu \mathrm{M})$. Control retinas were incubated in dark in the presence of neither drug. Quinpirole significantly decreased cAMP levels $(p<0.001)$; this effect of quinpirole was antagonized by L-745,870 $(p<0.001)$. The effect of the antagonist on cAMP levels in light was analyzed in retinas that were incubated in the light ( 2 min dark plus 7 min light) in the presence of $\mathrm{L}-745,870(L)$ at $10 \mu \mathrm{M}$ and $50 \mu \mathrm{M}$. Control retinas $(C)$ were incubated in light without the drug. Light significantly decreased cAMP levels $(p<$ $0.001)$, but the effect of light was unaffected by L-745,870 ( $p<0.616$ for $10 \mu \mathrm{M} ; p<0.503$ for $50 \mu \mathrm{M}) . N=5-6 /$ group.

Table 4. Dopamine utilization and synthesis in WT retinas, in vitro, in a medium containing glutamate

\begin{tabular}{llll} 
Mice & Conditions & Metabolite & Levels $(\mathrm{ng} /$ retina $)$ \\
\hline WT & Dark & DA & $0.426 \pm 0.02(n=6)$ \\
WT & Light & DA & $0.460 \pm 0.023(n=5)^{a}$ \\
WT & Dark & DOPA & $1.19 \pm 0.12(n=4)$ \\
WT & Light & DOPA & $0.921 \pm 0.11(n=4)^{b}$ \\
\hline
\end{tabular}

${ }^{a} p=0.291$ versus DA dark.

${ }^{b} p=0.150$ versus DOPA dark.

of glutamate should prevent light-evoked dopamine turnover. This hypothesis was tested by examining the effect of light on dopamine turnover in the presence of exogenous glutamate under conditions similar to those used to measure the light-evoked reduction of cAMP. To measure dopamine turnover, isolated retinas from WT mice were incubated in dark and light in medium containing glutamate and NSD-1015, an inhibitor of DOPA decarboxylase. Dopamine utilization was measured by the reduction in dopamine levels, whereas dopamine synthesis is measured by the accumulation of DOPA. The results shown in Table 4 demonstrate that there is no difference in residual dopamine levels in dark and light, indicating similar levels of utiliza- 


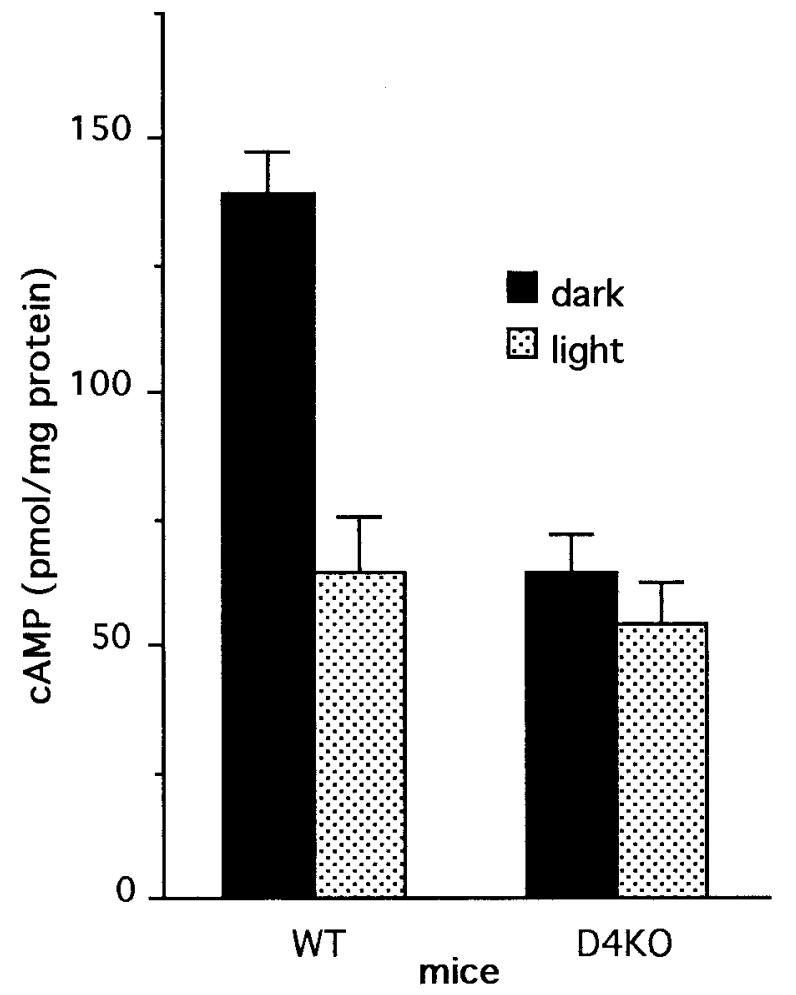

Figure 4. Regulation of cAMP by light in WT and D4KO retinas in the presence of exogenous glutamate. Isolated retinas were incubated in a medium containing glutamate and IBMX. Retinas were incubated in the dark for $9 \mathrm{~min}$, or for $2 \mathrm{~min}$ dark plus $7 \mathrm{~min}$ light. Two-factor ANOVA revealed a significant interaction of genotype and treatment $(F=15.438$; $p<0.001)$. Light significantly reduced cAMP levels in WT retinas $(p<$ $0.001)$ but not in D4KO retinas $(p=0.412)$. $N=5-6 /$ group.

tion. Furthermore, DOPA accumulation was not significantly affected by light exposure (Table 4). Hence, in the presence of exogenous glutamate, retinal dopamine neurons are not activated by light, providing further evidence that exogenous glutamate restricts light responses to photoreceptor cells. It should be noted that analysis of dopamine utilization and synthesis in vivo revealed robust light-evoked increases of DA turnover in both WT and D4KO retinas (data not shown). Together with the lack of effect of the dopamine D4 antagonist on the light-mediated suppression of photoreceptor cAMP levels, these observations indicate that in the glutamate-treated WT retina, light affects cAMP levels in photoreceptor cells directly, in a dopamine-independent manner.

Dysfunctional light-mediated regulation of cAMP formation in functionally isolated photoreceptor cells of D4KO mice

Illumination of WT retinas resulted in a 53\% reduction in cAMP levels from levels measured in dark (Fig. 4). In contrast, there was no significant reduction in cAMP levels in illuminated D4KO retinas, compared with dark-adapted D4KO retinas. Note that levels of cAMP in D4KO retinas incubated in darkness are $\sim 50 \%$ lower than those in dark-adapted WT retinas and are comparable with levels in illuminated WT retinas. These observations indicate that there is disruption of the direct, light-mediated reduction of cAMP formation in photoreceptors of mice lacking dopamine D4 receptors.

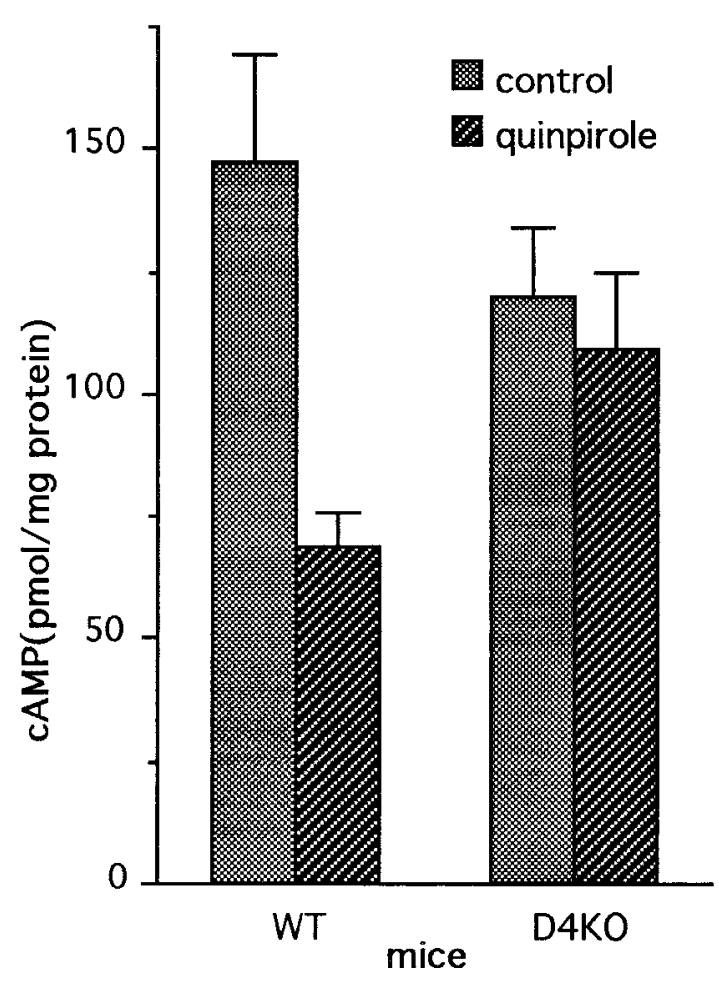

Figure 5. Regulation of cAMP in the dark in WT and D4KO retinas by quinpirole. Isolated retinas were incubated in medium containing glutamate with quinpirole $(1 \mu \mathrm{M})$ for $9 \mathrm{~min}$. Control retinas were incubated without quinpirole. Two-factor ANOVA revealed a significant interaction of genotype and treatment $(p=0.03)$. Multiple comparison by the Student-Newman-Keuls test indicated that quinpirole significantly reduced cAMP levels in WT retinas $(p=0.001)$ but not in D4KO retinas $(p=0.606) . N=5-6 /$ group.

Dysfunctionl quinpirole-mediated regulation of cAMP levels in retinas of $\mathrm{D} 4 \mathrm{KO}$ mice the dark

Cohen and Blazynski (1990) demonstrated that pharmacological activation of dopamine receptors with quinpirole, a D2/D3/D4receptor agonist, mimics the effect of light on cAMP levels in isolated mouse retinas incubated in the presence of exogenous glutamate (Cohen and Blazynski, 1990). This effect of quinpirole is thought to be caused by activation of dopamine D4 receptors located on photoreceptor cells (Cohen et al., 1992) but might also involve activation of inner retinal D2 and or D3 receptors, which also couple negatively to adenylyl cyclase. To measure the effect of quinpirole on D4 deficient retinas, dark-adapted WT and D4KO retinas were incubated in darkness with or without $1 \mu \mathrm{M}$ quinpirole (Fig. 5). In the WT retinas, a large reduction (50\%) in cAMP levels was measured in quinpirole-treated retinas, as compared with control. In the D4KO retinas, quinpirole had no significant effect on cAMP levels in the D4KO retinas (Fig. 5). The absence of effect of quinpirole in D4KO mice is consistent with the lack of D4 receptors and indicates that inner retinal D2 and D3 receptors do not contribute substantially to the cAMP response to quinpirole treatment. Thus, the $\mathrm{D} 4$ receptor subtype is primarily responsible for the quinpirole-mediated suppression of cAMP in WT retinas.

\section{Electroretinograms of WT and D4KO mice}

ERGs produced in the dark after $12 \mathrm{hr}$ of dark adaptation

There were no significant differences in a-wave amplitudes (repeated measures ANOVA, $p=0.9$ ) (Fig. 6A), b-wave amplitudes 


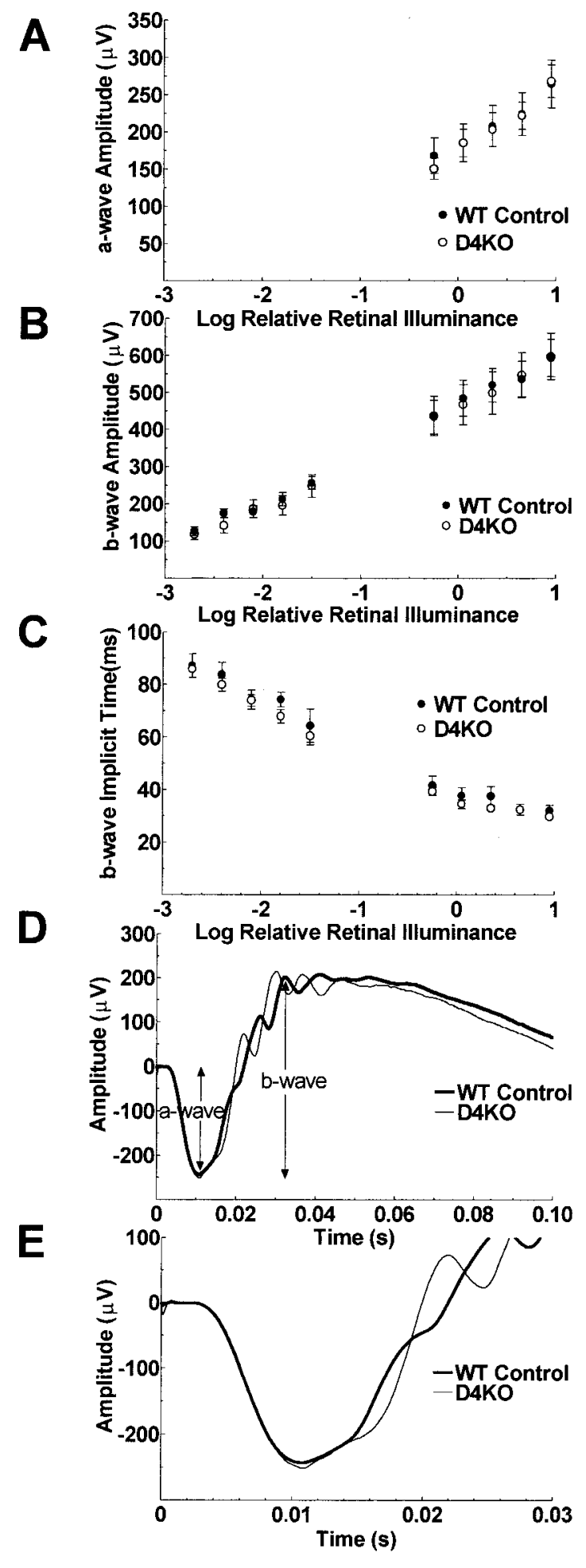

Figure 6. ERGs recorded from $12 \mathrm{hr}$ dark-adapted mice. The a-wave amplitudes $(A)$, b-wave amplitudes $(B)$, and b-wave implicit times $(C)$ of the ERGs of D4KO and WT mice are plotted as a function of flash illuminance presented during the dark after $12 \mathrm{hr}$ of dark adaptation. The lower limb of the function near a-wave threshold is not illustrated because the next lower flash illuminance available was too dim to produce an a-wave reliably. Error bars \pm SEM. $N=8(D 4 K O)$ and $9(W T)$. ERGs produced by stimulation of each mouse with the standard flash ( 9 scotopic $\left.\mathrm{cd} \cdot \mathrm{sec}^{-1} \cdot \mathrm{m}^{-1}\right)$ in the dark after $12 \mathrm{hr}$ of dark adaptation were averaged across the eight D4KO and nine WT controls separately and are presented graphically $(D)$ and with an expanded time scale focusing on the a-wave $(E)$. $(p=0.9)$ (Fig. 6B), or b-wave implicit times $(p=0.4)$ (Fig. 6C) of the 12 hr dark-adapted ERGs of the D4KO and WT control mice. In addition, there was no significant interaction of mouse type with flash intensity for a-wave or b-wave amplitude or b-wave implicit time ( $p=0.5,1.0$, and 0.8 , respectively). The a- and b-wave amplitudes increased and b-wave implicit times decreased significantly for both mouse types as a function of flash intensity ( $p<0.0001$ for all three measures).

ERGs averaged across all WT and D4KO mice separately are presented in Figure $6 D$. Figure $6 D$ illustrates the similarity in timing and in $\mathrm{a}-\mathrm{and} \mathrm{b}$-wave amplitudes produced by stimulation of WT and D4KO mice with the standard flash (9 scotopic $\left.\mathrm{cd} \cdot \mathrm{sec}^{-1} \cdot \mathrm{m}^{-1}\right)$ after $12 \mathrm{hr}$ of dark adaptation. In particular, the leading edges of the a-waves, which reflect the summed photoreceptor responses of the two groups, are superimposed. The time scale is expanded in Figure $6 E$ to show the similarity of the a-wave, particularly the descending slope, in more detail. The peaks of the first two oscillatory potentials of the D4KO mice occurred $\sim 5 \mathrm{msec}$ later than those of the wild-type mice ( $p=$ $0.0003,0.003)$. The amplitude of the first oscillatory potential of the D4KO mice was $\sim 50 \%$ larger than that of the wild type mice $(p=0.009)$ (Fig. 6D).

\section{ERGs produced during light adaptation to a rod-desensitizing background}

Throughout the time course of light adaptation, the b-wave amplitudes produced by stimulation of the D4KO mice with the standard flash were much smaller than those of the WT mice, from the earliest ERG that could be recorded (i.e., within $10 \mathrm{sec}$ of the onset of the background) (Fig. 7A). The averaged ERGs produced in D4KO and WT mice at 10 min during light adaptation by the standard flash are illustrated graphically in Figure $7 C$. The b-wave amplitude of the ERG of the D4KO mice is $\sim 50 \%$ of the amplitude of that of the WT mice with approximately equivalent b-wave implicit times (Fig. 7B). The a-wave amplitudes of the two mouse types were similar (data not shown). The difference in b-wave amplitude was statistically significant $(p<0.001)$, and the interaction between time and mouse type was not statistically significant $(p=0.2)$, indicating a difference in b-wave amplitude between the mice that did not vary with time during light adaptation. The b-wave amplitude increased significantly during light adaptation $(p<0.0001)$.

Figure $7 B$ shows the mean b-wave implicit time data as a function of time during light adaptation. The b-wave implicit times of D4KO and WT mice did not differ significantly during light adaptation ( $p=0.7$ ) nor was the interaction between mouse type and time statistically significant; but there was a statistically significant decrease in implicit time during light adaptation $(p=$ $0.003)$.

\section{ERGs produced during dark adaptation after 20 min of light adaptation}

The ERGs of the D4KO mice remained reduced compared with the WT controls during 12 min of dark adaptation (Fig. 8). Further dark adaptation data could not be gathered because anesthesia could not be maintained. Figure $8 A$ shows the a-wave amplitude of D4KO and WT mice as a function of time during dark adaptation. The difference in a-wave amplitude between the two mouse types was significant $(p=0.04)$. The a-wave amplitude increased with time during dark adaptation $(p<0.001)$, but there was no statistically significant interaction between mouse type and time during dark adaptation $(p=0.18)$. 


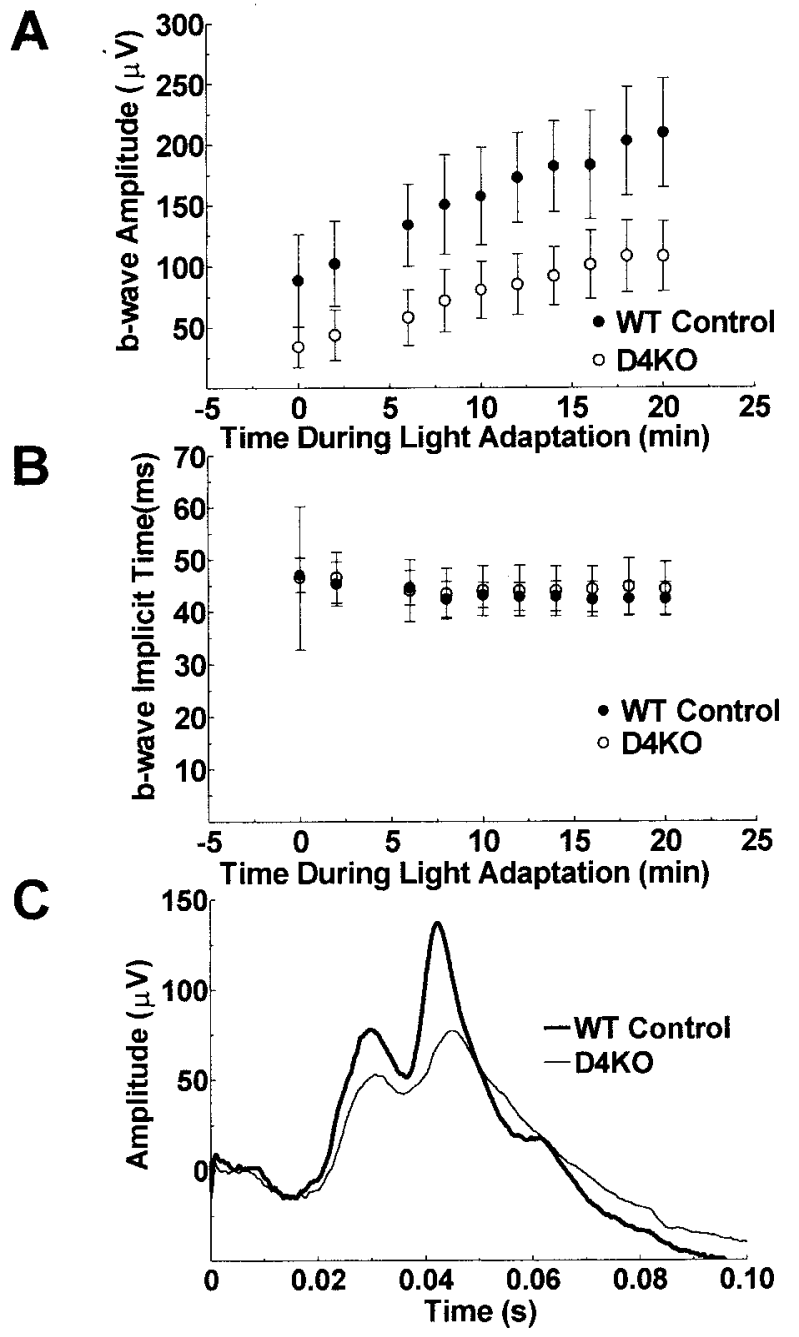

Figure 7. ERGs recorded in the first $20 \mathrm{~min}$ of light adaptation. The b-wave amplitudes $(A)$ and implicit times $(B)$ of the ERGs of D4KO and WT mice are plotted as a function of time during light adaptation to a rod desensitizing ganzfeld background $(58 \mathrm{~cd} / \mathrm{m})$. There is a gradual increase of b-wave amplitude during the 20 min light adaptation period and an initial decrease in b-wave implicit time in the first 6 min of light adaptation for both the D4KO and the WT mice. B-wave amplitudes are markedly depressed in D4KO mice compared with WT controls at all times during light adaptation. Error bars: $95 \%$ confidence interval. $N=6$ per group. ERGs produced by stimulation of each mouse with the standard flash after $10 \mathrm{~min}$ adaptation to a rod desensitizing ganzfeld background were averaged across the six D4KO and six WT controls separately and are presented graphically $(C)$.

The b-wave amplitude of D4KO mice as a function of time during dark adaptation was also reduced compared with that of WT mice $(p=0.03)$ (Fig. $8 B)$. The b-wave amplitude increased with time during dark adaptation $(p<0.001)$ but, despite a trend toward decreasing differences in the b-wave amplitudes of the two mouse types during the latter part of the dark adaptation period, there was no statistically significant interaction between mouse type and time during dark adaptation $(p=0.3)$. The b-wave implicit times of the D4KO mice were significantly longer than those of the WT control mice $(p=0.04)$ (Fig. $8 C)$, but there was no significant change in implicit time during dark adaptation $(p=0.3)$.

Figure $8 D$ shows the averaged ERGs produced by stimulation of the D4KO and the WT mice by the standard flash after $10 \mathrm{~min}$

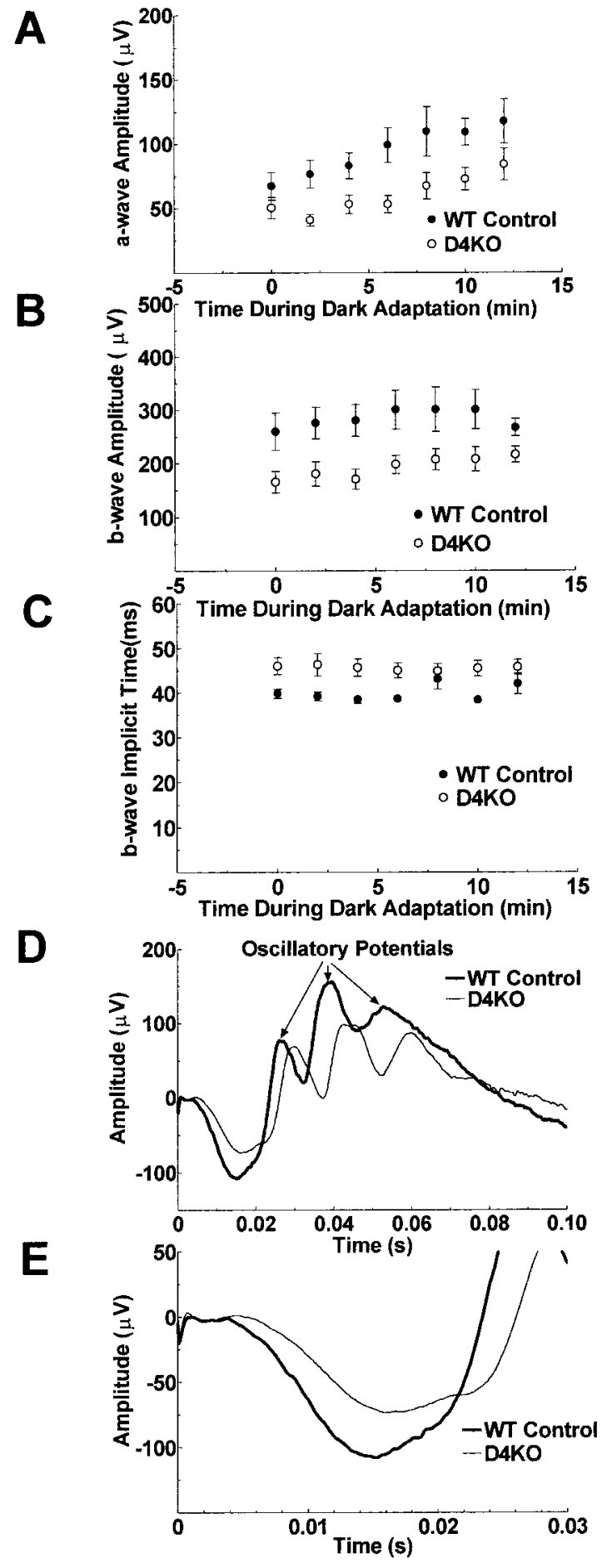

Figure 8. ERGs recorded in the dark after turning off the lighted background. The a-wave amplitudes $(A)$, b-wave amplitudes $(B)$, and b-wave implicit times $(C)$ of the ERGs of D4KO and WT mice are plotted as a function of time during dark adaptation after previous light adaptation for $20 \mathrm{~min}$ to a rod desensitizing, ganzfeld background. There is a gradual increase of a-wave amplitude during the $12 \mathrm{~min}$ dark adaptation period for both the D4KO and the WT mice. The a-wave and b-wave amplitudes of $\mathrm{D} 4 \mathrm{KO}$ mice were reduced from 2 to $10 \mathrm{~min}$ of dark adaptation compared with WT controls. The b-wave implicit times of D4KO mice were longer than those of WT mice. Error bars \pm SEM. $N=6$ per group. ERGs produced by stimulation of each mouse with the standard flash at $10 \mathrm{~min}$ in the dark after 20 min light adaptation were averaged across $\mathrm{D} 4 \mathrm{KO}$ and WT controls separately and are presented graphically $(D)$ and with an expanded time scale focusing on the a-wave $(E)$. 
of dark adaptation. This figure shows smaller a- and b-wave amplitudes and a prolonged implicit time of the b-wave of the D4KO. A slowing of the entire waveform starting with the onset and the descending slope of the a-wave is also apparent. The time scale is expanded in Figure $8 E$ to illustrate in more detail the difference in the onset and the leading edge of the a-wave of the two mouse types. The peak times of all four major oscillatory potentials of the D4KO mice were longer than those of the wild-type mice ( $p$ values from 0.001 to 0.009 ). The amplitudes of the oscillatory potentials of $\mathrm{D} 4 \mathrm{KO}$ and wild-type mice did not differ significantly.

\section{DISCUSSION}

Dopamine has been implicated in a multitude of retinal functions (for review, see Witkovsky and Dearry, 1991). Photoreceptor cells express dopamine D4 receptors (Cohen et al., 1992), which may mediate many of the effects of this neuromodulator within the retina. The possible roles of D4 receptors in retinal function were investigated in the present study by examining the morphology, biochemistry, and physiology of retinas lacking D4 receptors. Photoreceptor morphology and outer segment disc shedding after light onset were normal in D4KO mice. However, light-evoked suppression of photoreceptor cAMP synthesis was disrupted in retinas of $\mathrm{D} 4 \mathrm{KO}$ mice. In addition, ERG responses to a flash stimulus were reduced during light adaptation and dark adaptation in retinas lacking dopamine D4 receptors.

\section{Photoreceptor morphology}

The lack of dopamine D4 receptors had no effect on photoreceptor survival or morphology. The width of the outer nuclear layer, which contains the cell bodies of the photoreceptor cells, was comparable in retinas of WT and D4KO mice. Moreover, the length of the rod outer segments of the mutant mice was nearly identical to that of the WT. Pharmacological studies have suggested a role for dopamine in photoreceptor outer segment membrane turnover (Reme et al., 1986; Besharse et al., 1988). Photoreceptor outer segment disc shedding and phagocytosis by RPE are key steps in outer segment renewal throughout life (Young, 1967; Young and Bok, 1969). In the mouse retina, disc shedding peaks soon after light onset and then declines throughout the remainder of the day (Besharse and Hollyfield, 1979). Presently, morphological analysis of normal WT and D4KO photoreceptors, devoid of light-mediated cAMP regulation, did not reveal differences in disc shedding after light onset between the WT and $\mathrm{D} 4 \mathrm{KO}$ retinas, nor were abnormalities in outer segment structure observed that would be expected in the absence of balanced disc addition and removal.

The absence of overt abnormalities in photoreceptors of mice lacking D4 receptors is intriguing. Because the lack of DA D2 receptors has been suggested previously to alter the expression of compensatory mediators, thereby maintaining locomotor activity at a much higher level than observed after pharmacological blockade of the receptors (Kelly et al., 1998), the possibility of compensatory mechanism should be considered. Alternatively, direct effects of dopamine on photoreceptor cells might not be essential for the regulation of outer segment renewal. Despite the absence of apparent abnormalities in photoreceptor disc shedding in mice lacking D4 receptors, dopamine may modulate outer segment renewal by an action on the RPE. Because disc shedding requires the presence of adjoining RPE, the role of each cell type in the shedding process must be considered. The inhibition of disc shedding by cAMP in isolated amphibian eyecups requires the interaction of both photoreceptors and RPE (Besharse et al., 1982). Elevation of cAMP levels in cultured rat RPE cells inhibits the phagocytosis of isolated rod outer segments (Edwards and Flaherty, 1986). Mammalian RPE have dopamine D1a and D1b receptors that stimulate adenylyl cyclase activity (Versaux-Botteri et al., 1997; Haque et al., 2000). Thus, dopamine-mediated stimulation of cAMP levels in RPE may contribute to the daytime suppression of shedding and phagocytosis that occurs after the initial burst at dawn.

\section{Regulation of CAMP}

Illumination of WT retinas in vitro in the presence of glutamate, which restricts light responses to photoreceptor cells, caused a reduction in cAMP levels because of inhibition of cAMP formation in photoreceptors. This result confirms previous data in normal C57BL/6J mice by Cohen et al. (1992). The role of glutamate in limiting light responses to photoreceptors was illustrated in experiments where retinas were studied in vitro without exogenous glutamate. Under these conditions a smaller lightevoked reduction in cAMP levels was measured in WT retinas, which can be explained as a combined result of downregulation of cAMP in the photoreceptors and upregulation of cAMP caused by synaptic activation of neurotransmitter receptors elsewhere in the retina. Because photoreceptors constitute the majority of retinal neurons, the net result is a reduction in cAMP levels in illuminated retinas, but a reduction that is smaller than that observed when photoreceptor responses are functionally isolated.

Unlike the normal WT retina, incubation of the D4KO retinas in vitro, in a medium with glutamate, did not result in lightmediated reduction in cAMP levels. It is noteworthy that levels of cAMP in D4KO retinas in the dark were significantly lower than levels in WT retina when incubated in either the presence or absence of exogenous glutamate. Illumination of isolated D4KO retinas in the absence of exogenous glutamate resulted in an increase of cAMP levels, in striking contrast to the decrease of cAMP levels in light-exposed WT retinas. The increase of cAMP levels in illuminated D4KO retinas is apparently the net result of absence of light-mediated reduction of CAMP in photoreceptors lacking D4 receptors together with a dopamine D1 receptormediated increase elsewhere in the retina.

Application of quinpirole, a D2/D3/D4 receptor agonist, inhibits the light-regulated pool of cAMP in dark-adapted mouse retina (Cohen and Blazynski, 1990) presumably by activating D4 receptors on photoreceptor cells (Cohen et al., 1992). However, activation of D2 and D3 receptors also inhibits cAMP formation in neurons, raising the possibility that these receptor subtypes contribute to the cAMP response to quinpirole application in retina. In the present study, we found that quinpirole elicited large decreases of cAMP level of WT retinas, while having no significant effect in D4KO retinas. Thus, D2 and D3 receptors do not contribute significantly to the effect of quinpirole on retinal cAMP formation.

In normal retina, the suppression of photoreceptor cAMP synthesis by light may reflect a direct effect of light on the photoreceptor combined with a dopamine-mediated activation of D4 receptors, subsequent to transsynaptically mediated, lightevoked dopamine release from the inner retina. However, the inhibition of cAMP in functionally isolated photoreceptor cells of glutamate-treated retinas is apparently attributable solely to the direct effect of light on the photoreceptor cell and is dopamine independent. This conclusion is based on observations that exogenous glutamate eliminates transmission of light signals from 
the photoreceptor cells to the inner retina (Sillman et al., 1969; Dowling and Ripps, 1972), precluding light-evoked dopamine release from inner retinal neurons. Hence, the lack of lightevoked inhibition of cAMP formation in functionally isolated photoreceptors of D4KO mice was unexpected. However, Berson et al. (2001) recently presented evidence that some inner retinal neurons may be directly sensitive to light, raising the possibility that the cAMP response to light in glutamate-treated WT retina is caused by dopamine release and activation of the D4 receptors. This does not appear to be the case. We were unable to measure light-evoked activation of DA turnover in WT retinas incubated in the presence of exogenous glutamate. Furthermore, L-745,870, a D4-selective dopamine receptor blocker (Patel et al., 1997), antagonized the inhibition of cAMP levels in response to quinpirole, but had no effect on the light-mediated inhibition of cAMP levels of glutamate-treated WT retinas. Thus, the inhibition of cAMP formation by light in the presence of glutamate reflects a direct effect of light on the photoreceptor cell rather than a trans-synaptic effect mediated by dopamine. A likely mechanism for this direct effect is a coupling of photoreceptor membrane potential to adenylyl cyclase activity. Photoreceptor cells express type $1 \mathrm{Ca}^{2+} /$ calmodulin-activated adenylyl cyclase (Xia et al., 1993). Photoreceptors are depolarized in darkness (Werblin and Dowling, 1969; Hagins et al., 1970), leading to activation of voltage-gated $\mathrm{Ca}^{2+}$ channels (Fain et al., 1980; Barnes and Hille, 1989). Depolarization of photoreceptor cells leads to a sustained increase of intracellular $\mathrm{Ca}^{2+}$ (Uchida and Iuvone, 1999) and calcium-dependent activation of cAMP synthesis (Iuvone et al., 1991). Light exposure elicits a graded hyperpolarization of the photoreceptor cell membrane, closing the $\mathrm{Ca}^{2+}$ channels. This response presumably underlies the inhibitory effect of light on cAMP formation, as the effect of light can be mimicked by $\mathrm{Ca}^{2+}$ channel blockers in depolarized photoreceptor cells (Iuvone et al., 1991).

Why then is this direct effect of light dysfunctional in photoreceptor cells lacking dopamine D4 receptors? We propose the hypothesis that dopamine, via D4 receptors, normally modulates the cascade that couples membrane potential to adenylyl cyclase activity. This long-term modulation may exert a trophic action by regulating the expression of one or more components of the cascade, such as calmodulin or type 1 adenylyl cyclase. Such a trophic action would not be disrupted by short-term blockade of D4 receptors with antagonists. However, the complete absence of this modulation in photoreceptors lacking D4 receptors could result in deficiencies in expression or regulation of components of the cascade. Such an effect, which awaits investigation, is consistent with both the depressed levels of cAMP in darkness and the inability of light to inhibit cAMP formation in functionally isolated photoreceptors of D4KO mice.

\section{Physiological consequences}

In contrast to the apparently normal photoreceptor morphology and disc shedding, ERGs of D4KO mice were much smaller than those of the WT during light adaptation and in the first $10 \mathrm{~min}$ of dark adaptation. However, in fully dark-adapted retinas, there is no significant difference between D4KO and WT mice in timing, amplitude, or sensitivity of a- and b-waves, the major components of the ERG. This suggests that dopamine and/or cAMP do not appreciably impact the phototransduction response to a flash stimulus, but rather participate in slower, adaptive processes. The prolongation of the first two oscillatory potentials and the significant increase in amplitude of the first oscillatory potential of the
D4KO knock-out mouse indicates alterations occurring after phototransduction either at the photoreceptor synapse or postsynaptically. The first two oscillatory potentials, as well as the two later oscillatory potentials, of the D4KO mice were also prolonged during dark adaptation when there was a difference in the a-wave amplitudes of the two types of mice.

The ERG produced during light-adapted conditions is a cone ERG (Peachey et al., 1992; Toda et al., 1999). Therefore, the decreased b-wave amplitude of the light-adapted D4KO mouse indicates an abnormality either in the cone photoreceptors or cells postsynaptic to the cone photoreceptors. Dopamine D4 receptors are located on photoreceptors (Cohen et al., 1992; Tran and Dickman, 1992) and have not been found on bipolar cells (Nguyen-Legros et al., 1999). Thus, the decrease in the cone system b-wave of D4KO mice may reflect dysfunctional synaptic output and/or phototransduction of the cone photoreceptors. The a-wave seen in the average cone ERG was similar in D4KO and WT mice, but this small a-wave is difficult to detect in the ERGs of many individual mice (Peachey et al., 1992; Goto et al., 1995; Goto et al., 1996; this study) and, therefore, could not be quantified. As a consequence, it is not possible to distinguish between dysfuctional phototransduction and synaptic output as the cause of the decreased b-wave amplitude of the D4KO mice.

The ERG data indicate that the rod photoreceptors of the D4KO mice do not dark-adapt normally after bright prolonged light exposure. A photoreceptor abnormality could account, in part, for the altered postsynaptic response reflected in the b-wave reduction during adaptation. Therefore, both rod and cone photoreceptors of the D4KO mouse may have limited capacity to adapt to prolonged bright light exposure. It is likely that the leading edge of the a-wave during dark adaptation reflects the rod photocurrent (Lyubarsky and Pugh, 1996; Toda et al., 1999), because there is very little contribution from the cone system in the mouse dark-adapted ERG (Robson et al., 1990; Derwent and Linsenmeier, 2001; Robson and Frishman, 2000). Hence, the decreased a-wave amplitude and altered kinetics of the a-wave during dark adaptation implies abnormal generation of the photocurrent or of currents in the inner segment/synaptic terminals of the rods.

Absence of D4 receptors and light modulation of cAMP concentration in the D4KO mice could affect several mechanisms involved in the recovery phase of the photoreceptor response and postsynaptic gain: dephosphorylation of active opsin by rhodopsin phosphatase (Udovichenko et al., 1998), regulation of calcium channel current (Stella and Thoreson, 2000), and regulation of photoreceptor synaptic glutamate release by modification of calcium channel current (Schmitz and Witkovsky, 1997; Witkovsky et al., 1997). Disruption of the cAMP second messenger pathway could cause prolonged photoreceptor recovery, resulting in smaller and more sluggish responses similar to those in mice with null mutations of the gene for rhodopsin kinase (Lyubarsky et al., 2000). However, Jindrova and Detwiler (2000) found no effect of cAMP on the flash response of isolated lizard rod outer segments, consistent with the lack of effect of the D4 knock-out on the ERG of dark-adapted retina. Additionally, Jindrova and Detwiler (2000) found no effect of cAMP on recovery or adaptation in isolated outer segments. Thus, the abnormal adaptive responses of $\mathrm{D} 4 \mathrm{KO}$ retinas may be mediated by cAMPindependent mechanisms or by an effect of cAMP on the cell soma-synaptic terminals, where light-evoked changes of cAMP are prominent (Orr et al., 1976).

In conclusion, analyses of D4KO mice indicate that dopamine 
D4 receptors normally play a major role in regulating photoreceptor cAMP metabolism and adaptive retinal responses to changing environmental illumination.

\section{REFERENCES}

Barnes S, Hille B (1989) Ionic channels of the inner segment of tiger salamander cone photoreceptors. J Gen Physiol 94:719-743.

Berson DM, Dunn FA, Takao M (2001) Phototransduction by ganglion cells innervating the circadian pacemaker Invest Ophthalmol Vis Sci 42: S113.

Besharse JC, Hollyfield JG (1979) Turnover of mouse photoreceptor outer segments in constant light and darkness. Invest Ophthalmol Vis Sci 18:1019-1024.

Besharse JC, Iuvone PM (1992) Is dopamine a light-adaptive or darkadaptive modulator in retina? Neurochem Int 20:193-199.

Besharse JC, Dunis DA, Burnside B (1982) Effect of cyclic adenosine 3', $5^{\prime}$-mononphosphate on photoreceptor disc shedding and retinomotor movement. J Gen Physiol 79:775-790.

Besharse JC, Iuvone PM, Pierce ME (1988) Regulation of rhythmic photoreceptor metabolism: a role for post-receptoral neurons. In: Progress in retinal research (Osborne NN, Chader GJ, eds), pp 21-61. Oxford: Pergamon.

Cahill GM, Besharse JC (1991) Resetting the circadian clock in cultured Xenopus eyecups: regulation of retinal melatonin rhythms by light and $\mathrm{D}_{2}$ dopamine receptors. J Neurosci 11:2959-2971.

Civelli O, Bunzow JR, Grandy DK (1993) Molecular diversity of the dopamine receptors. Annu Rev Pharmacol Toxicol 33:281-307.

Cohen AI, Blazynski C (1990) Dopamine and its agonist reduce a lightsensitive pool of cyclic AMP in mouse photoreceptors. Vis Neurosci 4:43-52.

Cohen AI, Todd RD, Harmon S, O'Malley KL (1992) Photoreceptors of the mouse retina possess D4 receptors coupled to adenylyl cyclase. Proc Natl Acad Sci USA 89:12093-12097.

Dearry A, Burnside B (1986) Dopaminergic regulation of cone retinomotor movement in isolated teleost retinas. I. Induction of cone contraction is mediated by D2 receptors. J Neurochem 46:1006-1021.

Derwent JJ, Linsenmeier RA (2001) Intraretinal analysis of the a-wave of the electroretinogram (ERG) in dark-adapted intact cat retina. Vis Neurosci 18:353-363.

Dowling JE, Ripps H (1972) Adaptation in skate photoreceptors. J Gen Physiol 60:698-719.

Edwards RB, Flaherty PM (1986) Association of changes in intracellular cyclic AMP with changes in phagocytosis in cultured rat pigment epithelium. Curr Eye Res 5: 19-26.

Fain GL, Gerschenfeld HM, Quandt FN (1980) Calcium spikes in toad rods. J Physiol (London) 303:495-513.

Gingrich JA, Caron MG (1993) Recent advances in the molecular biology of dopamine receptors. Annu Rev Neurosci 16:299-321.

Goto Y, Peachey NS, Ripps H, Naash MI (1995) Functional abnormalities in transgenic mice expressing a mutant rhodopsin gene. Invest Ophthalmol Vis Sci 36:62-71.

Goto Y, Peachey NS, Ziroli NE, Seiple WH, Gryczan C, Pepperberg DR, Naash MI (1996) Rod phototransduction in transgenic mice expressing a mutant opsin gene. J Opt Soc Am A 13:577-585.

Grace MS, Chiba A, Menaker M (1999) Circadian control of photoreceptor outer segment membrane turnover in mice genetically incapable of melatonin synthesis. Vis Neurosci 16:909-918.

Hagins WA, Penn RD, Yoshikama S (1970) Dark current and photocurrent in retinal rods. Biophys J 10:380-412.

Haque R, Maltseva O, Ivanova T, Iuvone PM (2000) Dopamine D1 receptor expression in cultured human, monkey retinal pigment epithelial cells Invest Ophthalmol Vis Sci 41: S843.

Harrison JM, Nir I, Rubinstein M, Low MJ, Grandy DK, Iuvone PM (2000) Retinal function in dopamine D4 receptor knock-out (D4KO) mice. In: Vision science and its applications, OSA technical digest, pp 57-60. Washington, DC: Optical Society of America.

Hillman DW, Lin D, Burnside B (1995) Evidence for D4 receptor regulation of retinomotor movement in isolated teleost cone inner-outer segments. J Neurochem 64:1326-1335.

Iuvone PM (1986) Evidence for a D2 dopamine receptor in frog retina that decreases cyclic AMP accumulation and serotonin $N$-acetyltransferase activity. Life Sci 38:331-342.

Iuvone PM, Besharse JC (1986) Cyclic AMP stimulates serotonin $\mathrm{N}$-acetyltransferase activity in Xenopus retina in vitro. J Neurochem 46:33-39.

Iuvone PM, Galli CL, Garrison-Gund CK, Neff NH (1978) Light stimulates tyrosine hydroxylase activity and dopamine synthesis in retinal amacrine neurons. Science 202:901-902.

Iuvone PM, Gan J, Avendano G (1991) $\mathrm{K}^{+}$-evoked depolarization stimulates cyclic AMP accumulation in photoreceptor-enriched retinal cell cultures: Role of calcium influx through dihydropyridine-sensitive calcium channels. J Neurochem 57:615-621.

Jindrova H, Detwiler P (2000) Cyclic AMP has no effect on the gener- ation, recovery or background adaptation of light responses in functionally intact rod outer segments with implications about the function of phosducin. Vis Neurosci 17:887-892.

Kebabian JW, Calne DB (1979) Multiple receptors for dopamine. Nature 277:93-96.

Kelly MA, Rubinstein M, Phillips TJ, Lessov CN, Burkhart-Kasch S, Zhang G, Saez C, Bunzow JR, Fang Y, Gerhardt GA, Grandy DK, Low MJ (1998) Locomotor activity in D2 dopamine receptordeficient mice is determined by gene dosage, genetic background, and developmental adaptations. J Neurosci 18:3470-3479.

Kramer SG (1971) Dopamine: a retinal neurotransmitter. I. Retinal uptake, storage, and light stimulated release of H3-dopamine in vivo. Invest Ophthalmol 10:438-452.

Krizaj D, Gabriel R, Owen WG, Witkovsky P (1998) Dopamine D2 receptor-mediated modulation of rod-cone coupling in the Xenopus retina. J Comp Neurol 398:529-538.

LaVail MM (1976) Rod outer segment disk shedding in rat retina: relationship to cyclic lighting. Science 194:1071-1074; 1976.

Lowry OH, Rosebrough NJ, Farr AL, Randall RJ (1951) Protein measurement with the folin phenol reagent. J Biol Chem 193:265-275.

Lyubarsky AL, Pugh Jr EN (1996) Recovery phase of the murine rod photoresponse reconstructed from electroretinographic recordings. J Neurosci 16:563-571.

Lyubarsky AL, Chen C, Simon MI, Pugh Jr EN (2000) Mice lacking G-protein receptor kinase 1 have profoundly slowed recovery of conedriven retinal responses. J Neurosci 20:2209-2217.

Nguyen-Legros J, Berger B, Vigny A, Alvarez C (1981) Tyrosine hydroxylase-like immunoreactive interplexiform cells in the rat retina. Neurosci Lett 27:255-259.

Nguyen-Legros J, Moussafi F, Simon A (1990) Sclerally directed processes of dopaminergic interplexiform cells reach the outer nuclear layer in rat and monkey retina. Vis Neurosci 4:547-553.

Nguyen-Legros J, Versaux-Botteri C, Vernier P (1999) Dopamine receptor localization in the mammalian retina. Mol Neurobiol 19:181-204.

Nir I, Iuvone PM (1994) Alterations in light-evoked dopamine metabolism in dystrophic retinas of mutant $r d s$ mice. Brain Res 649:85-94.

Nir I, Haque R, Iuvone PM (2000) Diurnal metabolism of dopamine in the mouse retina. Brain Res 870:118-125.

Orr HT, Lowry OH, Cohen DI, Ferrendelli JA (1976) Distribution of $3^{\prime}: 5^{\prime}$-cyclic GMP in rabbit retina in vivo: selective effects of dark and light adaptation and ischemia. Proc Natl Acad Sci USA 73:4442-4445.

Patel S, Freedman S, Chapman KL, Emms F, Fletcher AE, Knowles M, Marwood R, Mcallister G, Myers J, Curtis N, Kulagowski JJ, Leeson PD, Ridgill M, Graham M, Matheson S, Rathbone D, Watt AP, Bristow LJ, Rupniak NM, Baskin E, Lynch JJ, RaganCI (1997) Biological profile of L-745-870, a selective antagonist with high affinity for dopamine D4 receptor. J Pharmacol Exp Ther 283:636-647.

Peachey NS, Arakawa K, Alexander KR, Marchese AL (1992) Rapid and slow changes in the human cone electroretinogram during light and dark adaptation. Vision Res 32:2049-2053.

Pierce ME, Besharse JC (1985) Circadian regulation of retinomotor movements. I. Interaction of melatonin and dopamine in the control of cone length. J Gen Physiol 86:671-689.

Remé C, Wirz-Justice A, Rhyner A, Hoffman S (1986) Circadian rhythm in the light response of rat retinal disk shedding and autophagy. Brain Res 369:356-360.

Robson JG, Frishman LJ (2000) A kinetic model of the contribution of the rod photocurrent to the electroretinogram. Invest Ophthalmol Vis Sci 41:s500.

Robson JG, Frishman LJ, Ahmed J, Viswanathan S (1990) Derived rod response and contributions of rod and off-pathway signals to the macaque electroretinogram a-wave. Invest Ophthalmol Vis Sci 40:s15.

Rubinstein M, Phillips TJ, Bunzow JR, Falzone TL, Dziewczapolski G, Zhang G, Fang Y, Larson JL, McDougall JA, Chester JA, Saez C, Pugsley TA, Gershanik O, Low MJ, Grandy DK (1997) Mice lacking dopamine D4 receptors are supersensitive to ethanol, cocaine, and methamphetamine. Cell 90:991-1001.

Schorderet M, Nowak JZ (1990) Retinal dopamine D1 and D2 receptors: characterization by binding or pharmacological studies and physiological functions. Cell Mol Neurobiol 10:303-325.

Schmitz Y, Witkovsky P (1997) Modulation of photoreceptor glutamate release by glutamate uptake blockers and dopamine. Invest Ophthalmol Vis Sci 38:s615.

Schwartz J-C, Giros B, Martres M-P, Sokoloff P (1992) The dopamine receptor family: molecular biology and pharmacology. The Neurosciences 4:99-108.

Shulman LM, Fox DA (1996) Dopamine inhibits mammalian photoreceptor $\mathrm{Na}+, \mathrm{K}+$-ATPase activity via a selective effect on the $\alpha 3$ isozyme, Proc Natl Acad Sci USA 93:8034-8039.

Sillman AJ, Ito H, Tomita T (1969) Studies on the mass receptor potential of the isolated frog retina. I. General properties of the response. Vis Res 9:1435-1442.

Stella Jr SL, Thoreson WB (2000) Differential modulation of rod and cone calcium currents in tiger salamander retina by D2 dopamine receptors and cAMP. Eur J Neurosci 12:3537-3548. 
Toda K, Nogami M, Murakami K, Kanaho Y, Nakayama K (1999) Colocalization of phospholipase D1 and GTP-binding-defective mutant of ADP-ribosylation factor 6 to endosomes and lysosomes. FEBS Lett 442:221-225.

Tran VT, Dickman M (1992) Differential localization of dopamine D1 and D2 receptors in rat retina. Invest Ophthalmol Vis Sci 33:1620-1626.

Uchida K, Iuvone PM (1999) Intracellular $\mathrm{Ca}^{2+}$ concentrations in cultured chicken photoreceptor cells: sustained elevation in depolarized cells and the role of dihydropyridine-sensitive $\mathrm{Ca}^{2+}$ channels. Mol Vision 5:1.

Udovichenko IP, Newton AC, Williams DS (1998) Regulation of the phosphorylation state of rhodopsin by dopamine. J Biol Chem 273:7181-7184.

Versaux-Botteri C, Martin-Martinelli E, Nguyen-Legros J, Geffard M, Vigny A, Denoroy L (1986) Regional specialization of the rat retina: catecholamine-containing amacrine cell characterization and distribution. J Comp Neurol 243:422-433.

Versaux-Botteri C, Gibert GM, Nguyen-Legros J, Vernier P (1997) Molecular identification of a dopamine $\mathrm{D}_{1} \mathrm{~b}$ receptor in bovine retinal pigment epithelium. Neurosci Lett 237:9-12.

Werblin FS, Dowling JE (1969) Organization of the retina of the mudpuppy Necturus maculosus. II. Intracellular recording. J Neurophysiol 32:339-355.
Witkovsky P, Dearry A (1991) Functional roles of dopamine in the retina. In: Progress in Retinal Res, Vol 11 (Osborne NN, Chader GJ, eds), pp. 21-61. Pergamon: Oxford.

Witkovsky P, Stone S, Tranchina D (1989) Photoreceptor to horizontal cell synaptic transfer in Xenopus retina: modulation by dopamine ligands and a circuit model for interactions of rod and cone inputs J Neurophysiol 62:864-881.

Witkovsky P, Nicholson C, Rice ME, Bohmaker K, Meller E (1993) Extracellular dopamine concentration in the retina of the clawed frog, Xenopus laevis. Proc Natl Acad Sci USA 90:5667-5671.

Witkovsky P, Schmitz Y, Akopian A, Krizaj D, Tranchina D (1997) Gain of rod to horizontal cell synaptic transfer: relation to glutamate release and a dihydropyridine-sensitive calcium current. J Neurosci 17:7297-7306.

Xia Z, Choi EJ, Wang F, Blazynski C, Storm DR (1993) Type I calmodulin-sensitive adenylyl cyclase is neural specific. J Neurochem 60:305-311.

Young RW (1967) The renewal of photorecepotor outer segments. J Cell Biol 33:61-67.

Young RW, Bok D (1969) Participation of the retinal pigment epithelium in rod outer segment renewal process. J Cell Biol 42:392-403.

Zawilska J, Derbiszewska T, Sek B, Nowak J (1995) Dopaminedependent cyclic AMP generating system in chick retina and its relation to melatonin biosynthesis. Neurochem Int 27:535-543. 